\title{
NUEVA REFORMA AGRARIA NEOLIBERAL Y MULTICULTURALISMO. TERRITORIOS INDÍGENAS, UN DERECHO VUELTO A NEGAR
}

\author{
María del Carmen Ventura Patiño ${ }^{\mathrm{i}}$ \\ COLMICH
}

\begin{abstract}
RESUMEN
En México, las «recomendaciones» en materia agraria emitidas por el Banco Mundial fueron plasmadas fielmente en las reformas legislativas aprobadas en 1992. Con estos cambios se ha pretendido otorgar certeza jurídica a los grandes inversionistas, a las inmobiliarias y trasnacionales, a través de diversos mecanismos como la desincorporación de la tierra del régimen social y su conversión en propiedad privada. Pilares de este proceso han sido los programas PROCEDE y PROCECOM, que han certificado y titulado algo más de $90 \%$ del total de los núcleos agrarios de nuestro país.

Una demanda reiterada del movimiento indígena impulsada principalmente a partir del levantamiento zapatista es la modificación del artículo 27 constitucional, en particular lo que refiere al reconocimiento del derecho colectivo que tienen los pueblos indígenas de sus tierras, territorios y recursos naturales. Un referente jurídico importante al que ha aludido el movimiento indígena es el Convenio 169 de la OIT, el cual fue ratificado por el gobierno mexicano en 1990.
\end{abstract}

En 2006, en la Cámara de Diputados se discutió una Iniciativa de una nueva Ley Federal Agraria en la que se proponía que los ejidos y comunidades que así lo desearan pudieran acogerse al procedimiento establecido para que sus propiedades fueran declaradas Tierras Indígenas, sin embargo, no se instituyó como nuevo régimen de propiedad ni se contempló el contenido jurídico de territorio señalado en el Convenio 169. Precisamente, en este trabajo intentaremos aportar algunos elementos que contribuyan al análisis sobre los alcances legales de esta Iniciativa.

Palabras clave: Tierra, reforma agraria, territorios, territorios indígenas.

\footnotetext{
${ }^{\mathrm{i}}$ Este trabajo es fruto del proceso de investigación que se realiza en el proyecto "Pueblos indígenas y reforma del Estado en América Latina”. (CONACYT), México. (Proyecto Núm. 4517).
} 


\begin{abstract}
World Bank «recommendations» on agrarian matters in Mexico were duly instated in legislative reforms approved in 1992. These changes aimed to provide legal security to large investors, real estate developers, and transnational corporations, through various mechanisms such as the disincorporation of land held under social systems and its conversion to private property. The PROCEDE and PROCECOM programs have been pillars of this process, to date granting certifications and property titles corresponding to just over $90 \%$ of all agrarian units in the country.
\end{abstract}

A reiterated demand of the indigenous movement, which gathered momentum especially following the Zapatista uprising, is the modification of Constitutional Article 27 , particularly in reference to the recognition of the collective right held by indigenous peoples over their lands, territories and natural resources. An important legal reference to which the indigenous movement has alluded is ILO Agreement 169, ratified by the Mexican government in 1990.

In 2006, Mexico's House of Representatives discussed a legislative proposal regarding a new Federal Agrarian Law, in which it was proposed that common-property lands (ejidos) and communities that so wished could adhere themselves to the established procedure so their properties would be declared Indigenous Lands. However, it was not instituted as a new tenure system, and the legal definition of territory as spelled out in ILO Agreement 169 was also not taken into account. In the present essay ${ }^{\mathrm{ii}}$ we attempt to offer some elements that contribute to an analysis of the legal scope of this proposal.

Key words: Land, agrarian reform, territories, indigenous territories.

\footnotetext{
ii This work is fruit of the research process carried out in El Colegio de Michoacán (COLMICH) in the framework of the project on «Indigenous Peoples and State Reform in Latin America» which receives support from the National Council on Science and Technology (Consejo Nacional de Ciencia y Tecnología- CONACyT), Mexico (Project No. 45,173).
} 


\section{ANTECEDENTES. UNA REVISIÓN GENERAL DE LAS REFORMAS}

El 6 de enero de 1992 se publicó el decreto que reformó el artículo 27 constitucional, dando fin a la base jurídica que había regulado la relación del Estado y los campesinos del México posrevolucionario. Las modificaciones a dicho artículo se apegaron sustancialmente a las «recomendaciones» que dictó el Banco Mundial para los países de América Latina, consistentes sustancialmente en adoptar una nueva política más acorde con el modelo neoliberal, donde compitieran libremente las fuerzas del mercado (Calva 1993). Entre las principales medidas legales aprobadas podemos señalar: 1. La conclusión del reparto agrario; 2. La apertura del campo a asociaciones y sociedades mercantiles; 3. La enajenación y renta de los derechos agrarios, y 4. La posibilidad de cambiar de régimen de propiedad.

Izar la bandera blanca del reparto agrario significó en los hechos la disolución de una conquista histórica, la cancelación jurídica de cualquier solicitud de tierras ya fuera para conformar nuevos núcleos agrarios o para la ampliación de los ya existentes. Como parte de ese mismo objetivo de otorgar certeza y seguridad jurídica a los inversionistas se aprobó y se ha promovido la creación de asociaciones y sociedades mercantiles, las cuales se han ido apropiando de grandes extensiones de tierra, incluidas no solo las parceladas de buena calidad y mejor ubicadas, ya sea en zonas turísticas o conurbadas, sino también de las tierras de uso común de los núcleos agrarios correspondientes a los agostaderos y bosques.

El menú de posibilidades para apropiarse de las tierras o de su riqueza es amplio, las otras opciones son a través de la compra, renta o bien de cambio del régimen de tenencia de la tierra, es decir, de la conversión de propiedad social a propiedad privada a través de la adquisición del dominio pleno. De esta manera, existen diferentes alternativas jurídicas para que el inversionista realice sus cálculos de costo-beneficio y se decida por la que le garantice una mayor plusvalía y el menor riesgo de conflicto social o agrario.

Parte fundamental de este paquete jurídico han sido los programas operativos impulsados a partir de 1993: el Programa de Certificación de Derechos Ejidales y 
Titulación de Solares Urbanos, Procede; y el Programa de Certificación en Comunidades, Procecom. Los cuales han tenido el objetivo de delimitar, destinar y asignar de manera individual la tierra de los núcleos agrarios. Programas que han constituido la premisa legal sin la cual no sería posible optar por las nuevas alternativas jurídicas. Lejos de lo que en su discurso manejan los responsables de ejecutar estos programas, no han sido aceptados en muchos ejidos y comunidades de manera voluntaria ni democrática, baste revisar su propio marco legal. El programa puede ser aprobado, por ejemplo, en una asamblea convocada por segunda ocasión con la mayoría de votos de los sujetos agrarios que asistan, es decir, la decisión puede recaer en un número de ejidatarios o comuneros poco representativo. Esa ha sido una de las salidas legales a partir de la cual las instituciones agrarias han logrado que el programa sea aceptado.

Adicional a ello hay que agregar la presión que ejercen sobre los núcleos las dependencias del sector agrario y agropecuario. Ejemplo de esto es el Programa de Apoyos Directos al Campo, Procampo, respecto del cual se ha determinado como política institucional — por lo menos así ha sucedido en los hechos- que los beneficiarios comprueben con el «certificado parcelario» los derechos sobre la tierra si quieren continuar recibiendo el precario apoyo económico. Esto ha influido para que ejidatarios y comuneros terminen por aceptar el Procede y el Procecom.

A 15 años de la aprobación de la reforma constitucional el avance de certificación ha sido notable. De los 29,942 núcleos agrarios existentes en nuestro país se han certificado 28,261, esto es un avance de 94\%, lo que representa en superficie 87,153, 914-27-60 hectáreas, es decir, 86\% del total de la superficie de propiedad social nacional. ${ }^{1}$ De los 1,681 núcleos restantes existe un número importante de comunidades que se han opuesto de manera contundente a aceptar el programa a pesar de la persistencia de las instituciones agrarias, también hay núcleos agrarios que por su problemática no han sido jurídicamente viable incorporarlos. Una de las razones principales son los viejos conflictos de límites entre los mismos ejidos y comunidades o con pequeños propietarios, algunos de ellos forman parte de lo que la Secretaría de la Reforma Agraria ha denominado programa de «Focos rojos». Otro impedimento es la 
situación jurídica de algunas comunidades que aún no cuentan con su carpeta básica, constituyendo lo que se conoce en términos jurídicos como comunidades de hecho y no de derecho. Según datos proporcionados por la propia Secretaria de Reforma Agraria, SRA, existen 1,504 núcleos considerados de atención especial, de los cuales 364 se han opuesto al programa; y 952 ejidos y comunidades catalogados como no programables de los cuales 106 no han aceptado el Procede ni el Procecom; el resto no ha sido posible incorporarlos al programa por conflictos de límites, invasión de tierras o bien por conflictos internos, entre las principales causas. ${ }^{2}$

Las manifestaciones de rechazo a la reforma del artículo 27 constitucional y su ley reglamentaria se hicieron presentes desde un inicio, diversas organizaciones campesinas e indígenas se pronunciaron en contra, sin embargo no tuvieron la fuerza y capacidad organizativa suficiente como para impedir su aprobación. A pesar de los avances expresados en los datos oficiales, las organizaciones han continuado realizando acciones en contra de estos programas mediante la difusión de sus implicaciones al interior de los núcleos, por ejemplo, el Encuentro Nacional contra el Procede y el Procecom realizado en febrero de 2003 en Chiapas, al que asistieron más de 80 organizaciones del sureste del país. Como resultado de un análisis de las consecuencias de la aplicación de dichos programas se acordó en este evento, entre otras cosas: 1. Rechazar el Procede y el Procecom; 2. Denunciar la forma en que se han impuesto; 3. Trabajar por la reconstitución de la comunidad; 4. Impulsar la autonomía, y 5. Revalorar la tierra. Así también se convino denunciar que estos programas han traído consigo la eliminación de las garantías de inalienabilidad, inembargabilidad, instransferibilidad e imprescriptibilidad de los bienes ejidales y comunales que garantizaban el patrimonio de las familias campesinas, indígenas y no indígenas, y de haber introducido prácticas individualistas que contravienen la organización social de estos núcleos. ${ }^{3}$

Como parte del seguimiento de los mencionados encuentros se efectuó otro en Michoacán en julio de 2006 al que asistieron 13 ejidos y comunidades procedentes de los estados de Michoacán, Jalisco, Nayarit, Durango, Distrito Federal, Guerrero, Oaxaca, Veracruz, Tabasco y Chiapas; con representación de 12 pueblos indígenas: purhépecha, mixteco, zapoteco, mixe, tlapaneco, náhuatl, ñahñú, tzeltal, tzotzil, cho’1, 
zoque y wirrarika, y 45 organizaciones populares, campesinas, estudiantiles e indígenas de distintas partes del país. Ahí se acordó: 1. Crear una Red Nacional por la Defensa de la Tierra y el Territorio y en contra de Procede y Procecom, con el objetivo de mantener un intercambio permanente de experiencias, y una coordinación y apoyo mutuo en sus luchas regionales y estatales; 2. Fortalecer la unidad comunitaria a través de asambleas, bajo una visión territorial y autonómica, y 3. Promover la construcción de alternativas comunitarias para el manejo y aprovechamiento sustentable de los recursos naturales. ${ }^{4}$

De cara a los datos «duros» sobre los avances de los programas en su versión oficial vale hacer algunas precisiones, no todos los núcleos que aceptaron el Procede o el Procecom certificaron y titularon la totalidad de sus tierras. Algunos de ellos, principalmente comunidades indígenas, solo acordaron la regularización de su perímetro, sin que se haya procedido a la medición y delimitación de las tierras al interior del núcleo. Recordemos que las tierras ejidales y comunales legalmente fueron divididas a través de estos programas en tierras de uso común, asentamiento humano y zona parcelada. Entonces, el hecho de que no se hayan medido representa que aunque hayan pasado por el Procede o el Procecom sus tierras no fueron asignadas en lo individual a los sujetos agrarios, salvaguardando de alguna manera la organización interna y/o colectiva de las tierras. Aunque no protegidas del acecho de los inversionistas.

En lo que se refiere a la creación de sociedades mercantiles cabe señalar que constituye una atractiva opción de acaparar grandes extensiones de tierra bajo el amparo de la ley. De acuerdo con la legislación está permitido que una sociedad mercantil pueda concentrar hasta 25 veces lo establecido para una pequeña propiedad, es decir, hasta 2,500 hectáreas de riego; 5,000 hectáreas de temporal; 10,000 hectáreas de agostadero; 3,500 hectáreas de algodón, o bien 7,500 hectáreas de plátano, entre otros cultivos. Para el caso de las tierras de pequeña propiedad ganadera en las que se realicen mejoras como introducción de riego, por ejemplo—, y se destinen a usos agrícolas, se seguirán computando como tierras ganaderas, aun cuando rebasen los límites establecidos para la pequeña propiedad, lo que representa otra opción más de acaparamiento. 
Pero el asunto de mayor peligro para los ejidos y comunidades en relación con las sociedades mercantiles es sin duda la aportación de sus tierras, que se consideran una vez incorporadas al patrimonio de la sociedad como acciones tipo «T». El único derecho que tienen los titulares de tales acciones es recibir tierra en pago en caso de liquidación, si es que quedan acciones una vez que se liquiden los adeudos. Esta figura jurídica permite la inversión extranjera hasta en $49 \%$. De acuerdo con datos del Registro Agrario Nacional, RAN, de 1992 a 2007 se han creado en todo el país 65 sociedades mercantiles y una sociedad civil, las que comprenden una superficie de 165,513-81-00.179 hectáreas. Los estados en los que se han constituido el mayor número de sociedades son Sonora (9), Distrito Federal (8), Nuevo León (7), Guanajuato (7) y Chiapas (6). ${ }^{5}$

Al participar los núcleos agrarios con el capital privado en sociedades mixtas podrán transmitir incluso el dominio de tierras de uso común a la sociedad mercantil, en abierta contradicción con lo que se establece en la fracción III del artículo 99 de la vigente Ley Agraria sobre las tierras comunales, que les confiere el carácter de inalienables, imprescriptibles e inembargables, «salvo» que se aporten a una sociedad mercantil. En estas sociedades las tierras pueden servir de prenda y enajenarse en caso de liquidación de la sociedad. Si bien se reconoce a los núcleos agrarios el derecho de preferencia para recibir tierra en pago, si es que tienen recursos para adquirirla, habrá que ver en qué condiciones productivas se encuentra la tierra una vez disuelta la sociedad (Ventura 1996).

La enajenación y renta de los derechos agrarios constituyen otra posibilidad jurídica para los inversionistas. Los cuales pueden elegir entre adquirir la tierra en propiedad o bien establecer un contrato de renta en términos que le resulten favorables. De las acciones jurídicas por enajenación que han sido registradas ante RAN solo de 2000 a junio de 2007, en el ámbito nacional, se reporta un total de 351,922 hectáreas; es en los estados de Veracruz $(30,320)$, Sinaloa $(26,905)$ y Tabasco $(22,370)^{6}$ donde se han dado el mayor número de casos. A estos datos hay que agregar las ventas que se efectúan fuera del procedimiento establecido por la ley y que por tanto no están reflejadas en estas estadísticas. Sobre el arrendamiento la legislación señala que la duración de los contratos puede ser no mayor a 30 años prorrogables. Sin embargo, puede darse el caso 
de que la tierra al momento que concluya el contrato se encuentre en un claro deterioro, por lo que es importante que esto se mencione en el clausulado del contrato, como recurso jurídico que otorgue protección al arrendador.

Una de las premisas legales fundamentales de las reformas fue el reconocimiento de los núcleos agrarios como entidades con capacidad jurídica para actuar y con patrimonio propio, es decir, se les otorga el carácter de propietarios sobre sus tierras ejidales y comunales, que se traduce en el derecho de usar, disfrutar y disponer de ellas. De esta manera, ahora tienen entre otras facultades jurídicas el poder modificar el régimen de propiedad, cambiar de pequeña propiedad a ejido y de ejido a comunidad, así como de comunidad a ejido, pero la acción legal sobre la cual los inversionistas han centrado su interés es el cambio de propiedad social a propiedad privada.

Sobre el cambio de propiedad privada a ejidal se han reportado, hasta junio de 2007, 169 acciones en 32 estados del país, que corresponden a una superficie de 78,439-4906.76 hectáreas. $^{7}$ Números que contrastan con la adopción del dominio pleno que han adquirido en parte de su superficie 2,761 núcleos agrarios, particularmente de ejidos, que comprenden los 32 estados de la república; la superficie que se ha desincorporado del régimen social es 1,621,696.08 hectáreas. Los estados donde se ha reportado el mayor número de hectáreas que ha modificado su tenencia de la tierra son Baja California (345,984.5354 has), Coahuila (297,896.8943 has) y Chihuahua $\left(182,468.6301\right.$ has). ${ }^{8}$ Solo por mencionar un dato que ejemplifica el interés sobre las tierras con riqueza natural, resalta el caso del municipio de Ensenada, en el estado de Baja California, en el que 52 de los 92 núcleos agrarios han adquirido en parte de su superficie el dominio pleno, tierras que seguramente han pasado a manos de empresarios extranjeros con capital en el ramo turístico.

Revisemos rápidamente el procedimiento señalado en la legislación para cambiar de régimen de propiedad. Se establece que se deberá contar con la aceptación de la asamblea, reunida en primera convocatoria con la asistencia de las tres cuartas partes del total de sujetos agrarios, o en segunda convocatoria con la asistencia de la mitad más uno, y la aprobación de las dos terceras partes de los asistentes; además de contar con la 
presencia de un representante de la procuraduría agraria y de un fedatario público. Lo que significa que una decisión de gran trascendencia para la vida del núcleo agrario puede recaer jurídicamente en unos cuantos, por ejemplo, en un ejido de 100 integrantes es suficiente la aprobación de 34 de ellos en segunda convocatoria, es decir, solo de una tercera parte del total de sujetos agrarios, quienes pueden disolver el régimen de propiedad social y borrar con su voto un proceso histórico de lucha por la tierra.

\section{TIERRA Y TERRITORIO, UN DERECHO DE LOS PUEBLOS INDÍGENAS}

La irrupción del Ejército Zapatista de Liberación Nacional, EZLN, en la vida política del país el 1 de enero de 1994 no fue casual. Resultó una respuesta a la entrada en vigor del Tratado de Libre Comercio, TLC, que representó, según declaración del propio subcomandante Marcos, un «acta de defunción de las etnias indígenas de México» (Bartra 1998). Pero otra de las motivaciones del levantamiento fue sin duda la reforma agraria neoliberal aprobada casi dos años atrás, que junto con el TLC no auguraban buenas nuevas para los cerca de cinco millones de campesinos pobres indígenas y no indígenas. Por ello, desde la Primera Declaración de la Selva Lacandona la demanda de la tierra constituyó una de las principales reivindicaciones del EZLN. ${ }^{9}$ Sin embargo, el gobierno federal se opuso desde un inicio a que el tema agrario fuera de los puntos primordiales a discutir en el proceso del diálogo con el EZLN, el cual finalmente se suspendió.

Es necesario señalar que las modificaciones en materia agraria aprobadas en 1992 se dieron en un marco de abierta contradicción con el contenido del Convenio 169 de la Organización Internacional del Trabajo, OIT, que nuestro gobierno había ratificado en 1990. De acuerdo con lo establecido en la Carta Magna, ${ }^{10}$ en la Convención de Viena Sobre el Derecho de los Tratados y en la Ley de Tratados, que rigen en el Estado mexicano, los convenios internacionales suscritos por el gobierno mexicano se convierten en ley suprema (López 2002). «Conforme al 133 constitucional su ratificación le hace formar parte de la ley suprema, lo cual implica que tiene el mismo rango que el resto de la legislación federal emanada de la Constitución y que las legislaciones estatales deberán atenerse a su contenido» (Gómez 2002: 266). 
Uno de los puntos nodales tratados en el Convenio 169 es el de territorio, que se define como «la totalidad del hábitat que los pueblos indígenas usan y ocupan de alguna manera». Sobre ello establece ciertas obligaciones para los gobiernos nacionales: «los gobiernos deberán respetar la importancia especial que para las culturas y valores espirituales de los pueblos interesados reviste su relación con las tierras o territorios o con ambos»; asimismo deberán reconocer y garantizar «el derecho de propiedad y de posesión sobre las tierras que tradicionalmente ocupan», y tomar medidas para salvaguardar el derecho de los pueblos a utilizar las tierras «a las que hayan tenido tradicionalmente acceso para sus actividades tradicionales y de subsistencia». Pero también reconoce ciertos derechos para los pueblos indígenas: «a participar en la utilización, administración y conservación» de los recursos naturales existentes en sus tierras y territorios (Sánchez 1999: 165); a «participar siempre que sea posible de los beneficios que reporten la explotación por parte del Estado de los recursos existentes en sus tierras» y a «recibir una indemnización equitativa por cualquier daño que puedan sufrir sus tierras como resultado de esas actividades» (Convenio 169, artículos 13-16).

Esta concepción de territorio fue un referente importante en los Acuerdos de San Andrés suscritos entre gobierno mexicano y EZLN, en los que se define que: «Todo pueblo indígena se asienta en un territorio que cubre la totalidad del hábitat que los pueblos indígenas ocupan o utilizan de alguna manera. El territorio es la base material de su reproducción como pueblo y expresa la unidad indisoluble hombre-tierranaturaleza» ${ }^{11}$.

La distinción e incorporación de una perspectiva integral de tierra y territorio contenida en el Convenio 169, así como la definición misma de territorio, representan un avance de gran trascendencia en términos jurídicos. Incluso con esto, el reconocimiento se queda corto porque no contempla el carácter de jurisdicción política de tales territorios indígenas. Mantiene el predominio del control del Estado sobre ciertos recursos naturales, en particular los del subsuelo. Y no define mecanismos claros de protección para los territorios indígenas. Sin embargo, es fundamental subrayar que constituye en 
materia de derecho internacional un poderoso referente jurídico para los pueblos indígenas en su lucha por la defensa de sus tierras y recursos naturales.

Finalmente el gobierno mexicano incumplió su palabra de enviar a las instancias de decisión nacional los Acuerdos de San Andrés, tampoco fue aprobada la llamada Ley de la Comisión de Concordia y Pacificación, COCOPA. En su lugar, en abril de 2001 el Congreso aprobó la Ley de Derechos y Cultura Indígena. En esta Ley el derecho territorial que se les reconoce a los pueblos indígenas está muy lejos de parecerse a lo dispuesto en el Convenio 169. Se limita su derecho a la «conservación y al mejoramiento del hábitat, y al uso y disfrute preferente de los recursos naturales de los lugares que habitan y ocupan las comunidades» ${ }^{12}$ (artículo 2, fracciones V y VI, CPEUM).

Tales disposiciones suprimen los conceptos de tierra y territorio, desconocen el derecho de propiedad y posesión, reducen su derecho de control colectivo a solo derecho de preferencia, negando su pertenencia territorial, su derecho a la territorialidad y a las facultades sobre sus territorios. Omiten explícitamente el concepto de territorio y lo convierten en lugares. Y solo se les confiere como derecho la conservación del hábitat, cuando este constituye una obligación social de todos los mexicanos. Por tanto, no se garantiza la integridad de los territorios indígenas ni se les otorga el uso y control colectivo de los recursos naturales en ellos contenidos. En resumen, «se despoja a los pueblos indios del espacio físico para el ejercicio de su autonomía» (Alonso 2002: 8).

A los pueblos indígenas no les basta con el reconocimiento de la propiedad de la tierra, es necesaria una garantía jurídica de protección de sus territorios; sólo de esta manera podrán proteger su cultura y su futuro como pueblos. Al respecto, Francisco López Bárcenas, intelectual indígena, nos advierte que «no debe confundirse el derecho de propiedad con el derecho de los pueblos indios a preservar los recursos naturales de su territorio o los lugares que consideran sagrados» (2002b: 125). Por ello, el concepto de territorio es imprescindible para entender y definir la idea que tienen los pueblos indígenas de la autonomía. 
Para Gustavo Montañez, se designa un territorio siempre que estemos asumiendo, aun de manera implícita, la existencia de un espacio geográfico y de un sujeto que ejerce sobre él cierto dominio, una relación de poder, una calidad de poseedor o una facultad de apropiación. La relación de pertenencia o apropiación no se refiere solo a vínculos de propiedad sino también a aquellos lazos subjetivos de identidad y afecto existentes entre el sujeto y su territorio. Ese sujeto individual o colectivo contiene generalmente una porción de poder suficiente para incidir en la transformación de ese territorio. El territorio es, pues, el espacio geográfico revestido de las dimensiones política, identitaria y afectiva, o de todas ellas (Montañez 2001: 21-22).

Mientras que la tierra no pasa de ser «la porción de un espacio geográfico con determinadas medidas que pertenece a alguien en propiedad, sea particular o colectiva, y que sirve para cultivarla y producir alimentos, para habitar o para construir una zona urbana que dé beneficios comunes a quienes en ella habitan» (López 2002b: 126).

Podemos decir que «el territorio es el espacio apropiado mítica, social, política o materialmente por un grupo social que se "distingue" de sus vecinos por prácticas espaciales propias» (Bonnemaison 1986, citado en Salmerón y Hoffmann 1997: 23). «El territorio representa para las comunidades indígenas el espacio geográfico de inscripción de la memoria colectiva, soporte material de su vida comunitaria y referente simbólico de su identidad colectiva» (Giménez 2000: 61). En el contexto del multiculturalismo, la dimensión cultural del territorio adquiere sentido político en la medida en que pretende legitimar su apropiación por un grupo. Por ello, «la reducción de lo territorial a su dimensión estrictamente cultural ocultaría el papel preponderante del territorio en la construcción de las jerarquías políticas, sea a nivel micro de las sociedades locales o en la relación con la sociedad global» (Hoffmann 2001: 16).

Del ejercicio de su derecho a la territorialidad, es decir, de la apropiación simbólica, material y sobre todo política del territorio por parte de los pueblos indígenas, depende su reproducción social, cultural y económica. Sin territorio no puede haber autonomía, de nada serviría que en la legislación se estableciera una serie de derechos en materia indígena si estos no pudieran ejercerse en un espacio geográfico determinado. Por ello, 
la demanda territorial es central en la reivindicación de autonomía de los pueblos indígenas de nuestro país, no solo por el control de los recursos, sino además en su dimensión política, de ahí que afirmemos que la lucha indígena es por el reconocimiento de la «autonomía político-territorial».

Como podemos apreciar, la reivindicación territorial tiene una estrecha relación con los derechos políticos, no solo con la representación y redistribución del poder sino además con los espacios de jurisdicción para el ejercicio de gobierno. En gran medida, lo que está en juego en esa disputa es precisamente el control del territorio, del cual depende la supervivencia económica y la reproducción cultural de los pueblos indígenas.

De esta manera la lucha actual por la autonomía no refiere únicamente la participación y representación política, sino, además a las facultades sobre sus territorios. Consideramos que sin territorio no puede haber autonomía, esta cobra sentido sobre una jurisdicción en la que se puede designar de acuerdo con la decisión comunal a sus gobernantes, pero el ejercicio de gobierno se cristaliza o se hace efectivo cuando se puede decidir el uso y aprovechamiento de los recursos naturales existentes en un territorio en favor de sus pobladores. De ahí que los derechos políticos y territoriales también tienen que ver, precisamente, con quién decide y en favor de quiénes se aprovechan los bienes naturales existentes en los territorios indígenas. Lo que subyace en el fondo es la disputa por el control y manejo de la riqueza natural concentrada en los territorios indígenas, por ello la negativa de los representantes gubernamentales en reconocer el derecho territorial de los pueblos indígenas.

\section{INICIATIVA DE LEY FEDERAL AGRARIA. UNA REFORMA NEOLIBERAL}

\section{CON DISCURSO MULTICULTURAL}

Uno de los compromisos establecidos en el Acuerdo Nacional para el Campo, ANC, que suscribieron el Ejecutivo Federal y diversas organizaciones campesinas del país en abril de 2003, fue la revisión del marco jurídico en materia agraria, ${ }^{13}$ con la 
participación del Consejo Nacional Consultivo del Sector Agrario, Conacosa. ${ }^{14} \mathrm{El}$ cual quedó integrado por los titulares de la Secretaría de la Reforma Agraria, de la Procuraduría Agraria y otros funcionarios de las dependencias del sector, representantes de organizaciones campesinas, de instituciones académicas y del sector privado rural. Sin embargo, dicha revisión se constriñó únicamente a la legislación secundaria sin trastocar el artículo 27 constitucional, por lo que sus alcances fueron restringidos desde un inicio.

De esta manera, en marzo de 2005, tras un largo proceso de trabajo que llevó más de un año, se presentó ante el pleno de la Cámara de Diputados la Iniciativa de una nueva Ley Federal Agraria. En esa sesión se acordó remitir dicha Iniciativa a la Comisión de Reforma Agraria para su análisis y elaboración del dictamen respectivo. Sin embargo, un mes después dos legisladores priístas en nombre de diversos grupos parlamentarios presentaron otras dos iniciativas que reforman y adicionan diversas disposiciones de la actual legislación en esa materia. Una de las propuestas la presentó una diputada de la Confederación Nacional Campesina, CNC, y secretaria de la Comisión de la Reforma Agraria. El documento señalaba que era resultado del trabajo de Conacosa y que contaba con el respaldo del ejecutivo federal, por lo que se cumplía con el acuerdo suscrito con las diversas organizaciones campesinas de modificar el marco legal agrario. Sin embargo varias de las organizaciones que integran Conacosa negaron su participación y manifestaron que era más bien una propuesta gubernamental que carecía de consenso.

La otra iniciativa fue entregada por el propio presidente de la Comisión de Reforma Agraria, que según sus palabras pretendía responder al vacío respecto «al proceso que se sigue ante los tribunales sobre la impartición de la justicia agraria» (García 2006: 128), asunto que la Iniciativa de la nueva Ley Federal Agraria no contemplaba.

Ante esto la Comisión de Reforma Agraria de la Cámara determinó analizar las tres iniciativas, para lo cual se formó un grupo plural de trabajo. Como resultado de todo un detallado proceso legislativo ${ }^{15}$ de discusión y análisis en el que participaron académicos, funcionarios, representantes de organizaciones sociales y campesinas, de instituciones 
públicas y privadas, del poder ejecutivo y legislativo; así como de la realización de foros, ${ }^{16}$ consultas y demás acciones descritas en el dictamen, en el que se afirma que fueron recogidas observaciones, comentarios y propuestas de diversos sectores relacionados con el campo; se presentó la Iniciativa con Proyecto de Decreto por el que se expide la Ley Federal Agraria.

En la justificación del dictamen del proyecto de ley se reconoce que la inversión productiva no fluyó como se auguraba con la reformas de 1992 y que el crédito agropecuario otorgado por la banca de desarrollo y el comercial disminuyó de manera importante: «en los últimos 20 años la inversión en fomento agropecuario se redujo en 95\%, el gasto público en $73 \%$ y el crédito agropecuario en $64 \%$. Los resultados de esto, aunado a otros factores, han sido estancamiento, dependencia alimentaria y agudización de la pobreza del sector» ${ }^{17}$.

Otro motivo que fundamenta lo apremiante de un nuevo marco jurídico es que el actual no contempla disposiciones que protejan los derechos de las poblaciones menos favorecidas, entre las que se encuentran las mujeres y los jóvenes del campo, y los pueblos indígenas, definiéndolos a todos por igual como «grupos vulnerables». Concepción que en principio muestra la continuidad de una visión político ideológica que no termina por reconocer el lugar histórico, social y político de los pueblos indígenas como sujetos que forman parte de esta nación, y por tanto de sus derechos específicos como colectividades culturalmente diferentes.

En la Iniciativa se considera pueblo indígena a «quienes habitaban el territorio antes de la Colonia, siendo trascendental en tal definición la conciencia de su identidad» ${ }^{18}$. Se señala que su importancia radica en que representan 6,830 ejidos y comunidades, los cuales comprenden una superficie de 22,000,000.00 hectáreas; 6,402 de estos núcleos cuentan con bosques y 971 con bosques y selvas; la mayoría de ellos se ubica en municipios con altas precipitaciones. En particular, las 2,192 comunidades comprenden una superficie de 17,000,000.00 de hectáreas, habitadas por 675,000 comuneros; ${ }^{19}$ localizadas muchas de éstas en zonas con alto potencial turístico y en áreas naturales protegidas, con una gran riqueza natural. 
El Proyecto de Ley Federal Agraria fue aprobado en lo general en la sesión de la Cámara de diputados el 13 de diciembre de 2005, con 241 votos a favor (110 del PRI, 114 del PAN, 6 del PRD y 1 independiente), 137 en contra (66 del PRI, 64 del PRD, 6 del PT y 1 independiente) y 15 abstenciones. ${ }^{20}$ Sin embargo en la sesión de 20 de abril de 2006, en la que se discutiría en lo particular el Proyecto de Ley, este no fue aprobado y fue remitido de nueva cuenta a comisiones, con la siguiente votación: 147 votos a favor (20 del PRI, 122 del PAN, 3 del PRD, 1 del PVEM y 1 independiente), 169 en contra (89 del PRI, 58 del PRD, 5 del PVEM, 1 del PT, 1 de Convergencia y 14 independientes) y 12 abstenciones.

Como podemos observar, el sentido de la votación del PAN se mantuvo a favor, al igual que la del PRD en contra, pero la del PRI cambio de manera determinante, en particular la de los legisladores pertenecientes a la Confederación Nacional Campesina. ${ }^{21}$

Una de las razones que explican el cambio, de acuerdo con lo señalado por el presidente de la Comisión de Reforma Agraria, también priísta, fue el proceso electoral federal: «La realidad era que la coyuntura político electoral estaba condicionando y hasta determinando la suerte de la Ley Federal Agraria, por varios factores. Por una parte, la CNC empezaba a ejercer presión con mayor firmeza al interior del PRI a fin de asegurar candidaturas para diputados y senadores» (García 2006: 150). Otro de los motivos fue la intromisión de organismos empresariales que no estaban de acuerdo con el contenido de la Iniciativa, los cuales se aliaron con el grupo parlamentario de CNC, como el Consejo Coordinador Empresarial, CCE. ${ }^{22}$ El escrito de la Cámara Minera de México dirigido al presidente de la comisión es revelador, su argumento refiere al artículo 27 constitucional que establece que la «ley protegerá la integridad de los grupos indígenas» y que de acuerdo con su interpretación sobre el artículo 2do. de la Carta Magna corresponde a las legislaturas estatales regular al respecto, por lo que concluye que no es el Congreso Federal la instancia facultada para legislar en la materia.

Lo anterior muestra, por un lado, un escenario de múltiples intereses partidarios, electorales y empresariales, por encima de los intereses de la mayoría de los productores 
del campo; por otro, pone en evidencia la influencia en la práctica política de los llamados poderes fácticos, que sin tener representación política ni facultad para legislar participan de manera decisiva en la vida jurídica y política de nuestro país. En efecto, sin los votos de CNC la Iniciativa se envío simplemente a la «congeladora» ${ }^{23}$. La siguiente legislatura decidirá si la asume o no como un asunto pendiente en su agenda.

No obstante que no fue aprobada, vale la pena esbozar algunos elementos para la reflexión. Para empezar, en el segundo párrafo del artículo 2do. de la presente Iniciativa de ley se establecen de manera clara los alcances jurídicos de los pueblos y comunidades indígenas: «Los tratados internacionales signados por el Estado mexicano, los principios generales de derecho y los sistemas normativos de los pueblos y comunidades indígenas, se invocarán en lo que fuere indispensable para completar las disposiciones de esta ley, siempre que dichas normas no se opongan a los principios contenidos en este ordenamiento» ${ }^{24}$.

A pesar de referir que los tratados y sistemas normativos servirán de manera complementaria en el ejercicio de la ley, se agrega el candado de «siempre y cuando» no contravengan a la presente disposición legal. Limitante jurídica que desde la Colonia se ha invocado, negando una vez más la posibilidad de una pluralidad jurídica. Pero además mantiene un marco legal contradictorio, como ya comentamos líneas arriba; el Convenio 169 es un tratado internacional que de acuerdo con lo establecido en la Carta Magna es ley suprema, es decir, el gobierno mexicano al firmarlo se compromete a cumplir lo establecido en dicho documento y a realizar las adecuaciones legales para garantizar el ejercicio de su contenido. Por lo que, en principio, hay un reconocimiento acotado y mantiene un marco jurídico que no permite su total cumplimiento.

En lo que se refiere a las tierras de los pueblos indígenas, en el cuerpo de la Iniciativa comprende una sola sección, la Octava: «De la protección de la integridad de las tierras, bosques y aguas de los pueblos y comunidades indígenas en ejidos y comunidades», incluida en el capitulo II del Título Tercero. Con ello se trata de dar respuesta a lo establecido en el párrafo segundo de la fracción VII del artículo 27 constitucional y a subsanar, de alguna manera, la inconsistencia jurídica del artículo 106 de la vigente ley 
agraria, que remite a su vez a una ley reglamentaria que nunca fue elaborada y que derivaría del desaparecido artículo 4to. constitucional de 1992. Sobre la Iniciativa trataremos de resaltar algunos puntos y formular varias preguntas que contribuyan al análisis, aunque de modo bastante general.

Se considera Tierras Indígenas de los pueblos y comunidades indígenas en ejidos y comunidades las que han sido dotadas, reconocidas, restituidas o incorporadas a su propiedad en el régimen ejidal o comunal y que hayan sido declaradas como tales en los términos de la ley. Al respecto, nos parece un acierto que no se siga considerando que los pueblos indígenas se circunscriben únicamente al régimen comunal, puesto que muchos ejidos cuentan con población indígena, en los que aún prevalece una organización social indígena en convivencia con las estructuras establecidas por la legislación agraria y civil. Por ello, la presente Iniciativa se referirá a las tierras indígenas de los pueblos y comunidades indígenas en ejidos y comunidades. Sin embargo, surge la interrogante: ¿aquellas comunidades que todavía no son comunidades de derecho - por no contar con su carpeta básica o la sentencia de un tribunal que las declare legalmente constituidas-, no podrán acogerse a los derechos aquí contenidos? Lo anterior adquiere importancia en virtud de que las comunidades en esa situación jurídica constituyen un número importante en el país, por lo que de acuerdo con esta Iniciativa seguirían al margen de la legalidad.

Se retoma la definición de pueblo indígena establecida en el Convenio 169 y se específica qué se entenderá por comunidad de un pueblo indígena: «aquellas que formen una unidad socioeconómica y cultural, asentadas en un territorio ${ }^{25}$ y que se reconocen a las autoridades propias de acuerdo con sus sistemas normativos, usos y costumbres» (art. 96 párrafo segundo). Aunque aquí se hable de territorio como un elemento importante para identificar una comunidad de pueblo indígena, en ningún artículo de la Iniciativa se reconoce el derecho al territorio por parte de los pueblos indígenas, en todo momento se refiere únicamente a tierras. Ya hemos hablado líneas arriba de la diferencia sustancial entre ambos conceptos y de sus implicaciones jurídicas. 
Una de las medidas que nos parecen positivas es que las tierras de los pueblos y comunidades indígenas mantienen su carácter de inalienables, imprescriptibles e inembargables, como lo señala la actual ley agraria, por lo que no podrá adoptarse el dominio pleno, ni podrán aportarse a sociedades mercantiles. Hasta aquí nos parece un avance importante porque pone los candados jurídicos de protección que han sido demandados por el movimiento indígena, sin embargo, a continuación se agrega la frase: «mientras conserven esta calidad». Por lo que, la Iniciativa mantiene un doble contenido: por un lado protege, y por otro se asegura de liberar los candados que garanticen el aprovechamiento de los recursos por terceros, la adquisición del dominio pleno o la aportación de las tierras de uso común a una sociedad.

La Iniciativa también mantiene en congruencia con la Constitución federal la propiedad de los ejidos y comunidades sobre los recursos naturales contenidos en sus tierras, «salvo» los que corresponden al dominio directo de la nación. Asimismo, establece que los recursos solo podrán ser aprovechados por sus integrantes, «salvo» que la asamblea determine el aprovechamiento por terceros, con una manifiesta utilidad para los núcleos agrarios. Entonces, de nueva cuenta primero protege y luego establece las llaves jurídicas que abren los candados.

Retomando de alguna manera lo señalado por el Convenio 169, se establece que en caso del aprovechamiento de los recursos del dominio directo de la nación se deberá consultar al pueblo o comunidad, con el fin de determinar si sus derechos serían perjudicados y en qué medida, antes de emprender alguna acción de aprovechamiento.

Al mismo tiempo se contempla que deberán participar, aunque con su «siempre que sea posible», de los beneficios derivados de tales actividades y ser indemnizados por daño o perjuicio que sufra su hábitat. Este mismo criterio se aplicará en caso de expropiación. De saberse perjudicados como resultado de una consulta se considerará para definir el monto de la indemnización así como las prestaciones que pudieran pactarse.

Sobre este punto, la Cámara Minera de México expresó su inconformidad al señalar que con esa disposición los pueblos y comunidades indígenas se ponían por encima de la 
potestad del Estado, dejando entrever no solo su desconocimiento jurídico sino además su temor de que se constituya en un instrumento legal que les impida la extracción de recursos y ponga en peligro la obtención de sus ganancias. Al respecto, el presidente de la Comisión de Reforma Agraria les respondió señalando que lo único que se hacía era «ajustar a la Ley los contenidos de los compromisos internacionales, como el Convenio 169 firmado por el presidente de la República y ratificado por el Senado, por lo que forma parte de nuestro sistema jurídico de acuerdo con el artículo 133 de la Constitución» (García 2006: 159).

En particular, sobre la consulta cabe precisar que actualmente los pueblos indígenas en el ámbito internacional reclaman su derecho a Libre Consentimiento Previo Informado, LCPI, lo que significa que cualquier proyecto que afecte a los pueblos indígenas deberá contar con su permiso y consentimiento antes de iniciar cualquier obra; de esta manera se reconoce su derecho al territorio, a su cultura y a sus formas de vida. ${ }^{26}$ Mientras que la consulta no garantiza ningún derecho a detener proyectos que les afecten o impacten negativamente. La consulta en los hechos no obliga a la parte gubernamental a respetar lo señalado por los sujetos agrarios involucrados. El derecho a LCPI ha quedado asentado en la Declaración de las Naciones Unidas sobre los Derechos de los Pueblos Indígenas, que fue aprobada recientemente por el Consejo de Derechos Humanos de Naciones Unidas, en septiembre de $2007 .{ }^{27}$ Sin embargo, toda vez que jurídicamente no es vinculante y que se suprimió del proyecto original la disposición de que las Naciones Unidas crearían un órgano específico encargado de vigilar el cumplimiento de la Declaración por parte de los Estados nacionales, su aplicación está sujeta a la voluntad política de los distintos gobiernos nacionales que la suscribieron.

Por otra parte, la Iniciativa establece que para adquirir la calidad de Tierras Indígenas y adoptar la protección de sus tierras, bosques y aguas, deberá ser resultado de un acuerdo de asamblea, cumpliendo las formalidades especiales previstas en la presente ley para las fracciones X a la XXIII; a esto en términos operativos se le denomina «asamblea dura». Lo que dará lugar a la tramitación de la declaratoria de Tierras Indígenas mediante la jurisdicción voluntaria que deberá efectuarse ante el Tribunal Agrario. 
Para ello será necesario demostrar entre otras cosas: 1) La legal existencia del ejido o comunidad; 2) El acuerdo de asamblea en la que se adoptó la calidad de Tierras Indígenas con las formalidades previstas en esta ley; 3) La propiedad y posesión de las tierras, y 4) Su pertenencia a un pueblo indígena. De acuerdo con los requisitos señalados, se excluye, en principio, a las comunidades de hecho, para quienes esta hubiera sido una opción jurídica que resolviera en definitiva su situación.

Sobre el segundo punto, puede representar un procedimiento un tanto complicado, veamos el porqué. Para la asistencia en primera convocatoria según lo establece el proyecto de ley deberán estar presentes las tres cuartas partes de los integrantes del núcleo para declarar válida la asamblea, o bien en segunda convocatoria deberán estar presentes por lo menos la mitad más uno y la aprobación deberá ser por las dos terceras partes. El problema radica en que solo podrán participar quienes comprueben su calidad de sujetos agrarios con la documentación señalada por el proyecto de ley, lo cual en muchos de los casos no coincide con los criterios de membresía étnica establecidos por los pueblos o comunidades indígenas, por ejemplo, en algunas comunidades se consideran como comuneros quienes hayan nacido en la comunidad, participen en las fiestas y en los trabajos en beneficio de la colectividad. Así, los valores y costumbres comunales no tienen un reconocimiento legal, reproduciendo de nueva cuenta un enfrentamiento entre la visión de identidad étnica y el sujeto de derecho definido por el derecho positivo. Aunque la Iniciativa contemple la posible aprobación de su calidad agraria por parte de la asamblea, el asunto es que para poder realizarla es necesario que se parta del reconocimiento de que no son comuneros y declarar válida la asamblea solo con los sujetos que cumplan con los requisitos señalados por la legislación.

En el capítulo V de la presente Iniciativa, titulado «De las Comunidades», ya se incorpora como criterio para acreditar la calidad de comunero el que se haya nacido en la comunidad o cumpla los requisitos establecidos en el estatuto comunal, en ambos casos de todas maneras deberá ser reconocido por la asamblea, de acuerdo con el procedimiento establecido por el derecho positivo. El procedimiento o requisitos para el reconocimiento de los integrantes o sujetos de derecho de las Tierras Indígenas es un tema que no fue abordado, o por lo menos no quedó plasmado en la Iniciativa, a menos 
que se entienda que serán aquellos señalados para los ejidatarios y comuneros, que por cierto son diferentes.

En relación con el tercer punto nos parece que pudieran presentarse algunas dificultades. Hay algunos núcleos agrarios, en particular comunidades, que a pesar de que son propietarias de sus tierras no tienen toda la superficie en posesión, por lo que este puede ser un impedimento legal para apelar a tal protección. Respecto a la acreditación de su pertenencia a un pueblo indígena, aún no queda del todo claro el procedimiento, se dice que la conciencia de su identidad indígena deberá ser un criterio fundamental, pero en la propia Ley de Derechos y Cultura Indígena no se específica ningún recurso. En el artículo 2do. de la Constitución nacional se delega a las constituciones y leyes de las entidades federativas para que establezcan las normas de dicho reconocimiento, las que deberán tomar en cuenta el criterio etnolingüístico y de asentamiento físico. Entonces, cabe preguntar si en todos los estados donde no se haya reglamentado al respecto, los pueblos y comunidades indígenas ahí asentados no podrán recurrir a esta protección. O bien, en los que ya se cuente con una reglamentación y sus criterios de identificación haya excluido a núcleos agrarios que se autoadscriban como indígenas, estos tampoco podrán acogerse a dicho procedimiento. En fin, son preguntas que van más allá del mero procedimiento.

Asimismo, una vez declaradas Tierras Indígenas podrán acudir de nueva cuenta al Tribunal para solicitar que: 1) Se restrinjan las actividades de terceras personas en sus tierras cuando representen valores culturales y de identidad contrarios a los usos y costumbres de los pueblos y comunidades indígenas, y 2) Se permita el acceso a los lugares sagrados o centros ceremoniales de los pueblos o comunidades, que hayan sido previamente declarados como tales por autoridad competente y que se encuentren fuera de sus tierras.

A modo de propuesta hubiera sido pertinente que en el mismo procedimiento de declaración de Tierras Indígenas se incluyeran estas protecciones jurídicas, de otro modo, se presentan varios trámites que realizar, lo que se traduce en tiempo y recursos. Además, vale preguntar a partir de qué criterios se determinará qué tierras encierran 
valores culturales, ante qué instancia se solicitará que se declare el valor cultural; de igual manera, cuál será el procedimiento para declarar un lugar sagrado y cuál es la autoridad competente que lo certificará.

Otra disposición legal importante es que las autoridades agrarias respetarán y garantizarán las modalidades de uso y disfrute de las tierras de los pueblos y comunidades indígenas en ejidos y comunidades, así como la cesión o transmisión de derechos al interior de éstos, de acuerdo con las instituciones sociales, económicas, culturales, políticas y sistemas normativos del pueblo o comunidad correspondiente, sujetándose a los principios generales de la Constitución. Nos parece que este artículo recoge un reclamo reiterado por parte de los núcleos agrarios: que se respeten sus formas de organización para el aprovechamiento de sus tierras, así como sus criterios específicos para la cesión o transmisión, aunque surge la interrogante en los casos donde la costumbre es heredar por partes iguales a todos los hijos hombres y mujeres, si el derecho podrá ser divisible y si se podrá reconocer a todos su calidad agraria como sujetos de derechos al interior de esos núcleos.

De manera general podemos comentar que la Iniciativa mantiene un doble contenido, por un lado otorga protección jurídica pero por otro establece los mecanismos que liberan los candados; en ese sentido, se garantiza el aprovechamiento de los recursos por terceros, ya sea a través de sociedades mercantiles o por medio de la adquisición de dominio pleno.

Por último, nos parece pertinente y estamos totalmente de acuerdo en que se creen mecanismos de protección para las tierras habitadas por indígenas, pero qué hay de las tierras habitadas por millones de campesinos pobres no indígenas que por no ser indígenas no tienen derecho a tal protección. No se trata de subestimar los avances en esta materia, pero sí de insistir en la necesidad de reformar el artículo 27 constitucional y de diseñar marcos legales que respondan a las necesidades de todos los habitantes del campo, tendientes a superar el atraso y la pobreza en la que se encuentran, no solo a través de la legislación sino también a partir de políticas públicas adecuadas, además de 
los recursos suficientes para invertir e incentivar la producción, que les permita contar con condiciones para competir en el mercado.

Por otra parte, sostenemos que sería más loable y de avanzada que la presente Iniciativa fuera a la inversa, es decir, debería declarar por decreto dicha protección para todos los núcleos, y establecer como una opción el procedimiento para aquellos que decidan dejar de gozar de tal protección jurídica. Eso ahorraría tiempo y recursos, pero más allá de ello se cumpliría con la obligación estatal de respetar el carácter inembargable, imprescriptible e inalienable de la propiedad social, que representa cerca de la mitad del territorio nacional.

Una pregunta general es: ¿por qué no reconocer también las Tierras Indígenas como un régimen de propiedad y no únicamente como una modalidad jurídica? La Iniciativa significa un avance importante, como resultado de un largo proceso de debate y análisis entre diversas fuerzas no solo al interior del sector campesino e indígena sino también de los poderes legislativo y ejecutivo, con la participación de la iniciativa privada del campo, de las instituciones agrarias y académicas; por lo que el documento tiene la virtud, en el decir de algunos, de gozar del consenso de todos estos actores. ${ }^{28}$ A pesar de todo ello, no sobra seguir haciendo hincapié en la urgencia de realizar reformas profundas en materia agraria y en derechos indígenas de manera integral, que comprendan la legislación primaria y secundaria, normas a las instituciones y el diseño de políticas públicas acordes con los nuevos cambios jurídicos, así como de los presupuestos que garanticen el cumplimiento de tales metas.

\section{COMENTARIOS FINALES}

Es importante aclarar que el presente documento es un ejercicio de reflexión general y parcial, porque únicamente se centra en la sección octava. Falta una revisión minuciosa del conjunto de la Iniciativa de Ley Federal Agraria, de tal manera que haya congruencia jurídica en todo el cuerpo de la propuesta con lo establecido para las Tierras Indígenas. Un análisis profundo deberá incluir también los puntos que generaron 
mayor rispidez en el debate entre los diversos actores y la respuesta de las distintas fuerzas campesinas e indígenas.

Lo que sí es claro es que los alcances jurídicos de la legislación secundaria, por muy avanzados que puedan ser, se verán siempre acotados si no se realizan reformas profundas al artículo 27 constitucional que contemplen en su acepción amplia el derecho a la tierra y al territorio, así como al uso, control y aprovechamiento de los recursos naturales ahí contenidos por parte de los pueblos indígenas. Para ello será necesario un esfuerzo mayor en la suma de voluntades políticas de los distintos actores tendiente a tener la disposición de revisar en serio no solo el marco legal nacional, también en el diseño de políticas públicas que respondan a las necesidades estructurales de los habitantes del campo, indígenas o no indígenas.

Más allá de buscar dar cumplimiento con lo dispuesto en el artículo 27 constitucional en relación con la protección de la integridad de las tierras de los grupos indígenas, también esta Iniciativa trata de dar respuesta a los reclamos del movimiento indígena y contribuye a crear un escenario ante la comunidad internacional sobre que el gobierno mexicano es congruente con lo pactado en los tratados internacionales, pero incluso de cara a los organismos financieros, los cuales incluyen dentro de sus políticas el que los gobiernos nacionales incorporen adecuaciones jurídicas y definan planes y programas de desarrollo en atención a los pobres, en especial hacia los indígenas.

Lo anterior nos remite a lo que denomina Donna Van Cott (2000) «constitucionalismo multicultural», que refiere al proceso de reformas jurídicas que han realizado una serie de países en América Latina en respuesta a la lucha por el reconocimiento de los derechos indígenas colectivos a la tierra (citado en Hale 2002: 1). Sin embargo, frente a esto que parece ser resultado de una conquista del movimiento indígena, Charles Hale nos llama a la reflexión sobre la premisa de quienes sostienen que «las luchas indígenas e ideologías neoliberales se encuentran fundamentalmente opuestas entre sí, de cualquier convergencias que se pueden detectar son resultado [sic] ya sea de las consecuencias no previstas de las reformas neoliberales o bien de los logros anteriores de la resistencia indígena» (Hale 2002: 2). Al respecto, su argumento es que dicha 
premisa resulta incompleta y engañosa porque descuida un aspecto de la relación que denomina «multiculturalidad neoliberal», consistente en que los promotores de la doctrina neoliberal apoyan de modo proactivo una versión importante, si bien limitada, de los derechos culturales indígenas, como medio de resolver sus propios problemas y avanzar en sus propias agendas políticas (ibid).

En una entrevista que sostuvo Charles Hale con una funcionaria oficial del Banco Mundial encargada de un proyecto importante para promover la «modernización agrícola» en Guatemala, justamente en relación con las tierras indígenas, la funcionaria señaló que no compartía la idea de quienes consideran que los derechos a tierras comunitarias son un bien social y una demanda universal de los pueblos indígenas, que de ser así se asumiría lo que la gente quiere sin preguntarle y sin darles la oportunidad de elegir. Por lo que, los principios de libertad individual y el derecho a la elección deben garantizarse.

A la luz de ello, cabe preguntarse si la Iniciativa de ley en materia agraria en nuestro país no encaja en lo que Hale llama «multiculturalismo neoliberal», cumpliendo varios propósitos; por un lado, se presenta la Iniciativa como una respuesta a la demanda de protección de sus tierras por parte de algunas organizaciones indígenas, estableciendo el procedimiento para quienes como resultado de una «elección» puedan acogerse a tal protección, aunque por otro mantiene y garantiza a la vez las disposiciones jurídicas que salvaguardan los intereses de los inversionistas para apropiarse, concentrar, explotar y aprovechar las tierras y recursos naturales propiedad de los pueblos indígenas. Al mismo tiempo, se proyecta ante las instancias internacionales una imagen de credibilidad política, de atención a lo pactado en los convenios internacionales y de cumplimiento con las exigencias de los organismos financieros.

Así, para que no se presuma como una Iniciativa de reforma agraria neoliberal con discurso multicultural deberá dar respuesta integral a la reivindicación territorial de los pueblos indígenas, donde se reconozca, proteja y garantice el derecho colectivo a la organización material y simbólica de un espacio geográfico en el cual el pueblo indígena tenga el control y capacidad de imponer su propia normatividad y sus formas 
de gobierno. Esto es, que se exprese en sus dos dimensiones, la material: en el uso, goce y manejo de los recursos naturales; y la inmaterial, es decir, la simbólica y la política: en el control sobre los procesos de orden político, económico, social y cultural que aseguren su reproducción y continuidad material y simbólica (Zúñiga 1998). 


\section{BIBLIOGRAFÍA}

Alonso, Jorge, 2002, El Zapatismo y la nueva ley indígena en México. Guadalajara, Jalisco Mecanoescrito.

Bartra, Roger, 1998, «Sangre y tinta del kitsch tropical». En Fractal, año 2, volumen III, núm. 8, enero-marzo.

Calva, José Luis, 1993, La disputa por la Tierra. Fontamara, México.

Constitución Política de los Estados Unidos Mexicanos, 1994. Ediciones Delma, México.

—, 2003. Ediciones Delma, México.

Diario Oficial de la Federación, 23 de diciembre de 1996. México.

Dictamen de Proyecto de Decreto por el que se crea la Ley Federal Agraria, 2005. Mimeografía. México.

García, Manuel, 2006, El proceso legislativo y los grupos de presión. El caso de la Ley Federal Agraria. MC editores, México.

Giménez, Gilberto, 2000, «Territorio, cultura e identidades. La región socio-cultural». En Globalización y regiones en México, coordinado por Rocío Rosales. PUECPorrúa, México.

Gómez, Magdalena, 2002, «Derecho indígena y constitucionalidad». En Antropología Jurídica: perspectivas socioculturales en el estudio del derecho, editado por Esteban Krotz. Anthropos-UAM Iztapalapa, Barcelona, España.

Hale, Charles, 2002, ¿Puede ser el multiculturalismo una amenaza? Gobernabilidad, derechos culturales y política de identidad en Guatemala. University of Texas en Austin. Documento.

Hoffmann, Odile, 2001, Territorios de conflicto y cambio socio-cultural. II Seminario internacional sobre Territorio y Cultura, de 23 a 27 de octubre. Universidad de Caldas, Manizales, Colombia.

Ley Agraria, 1993. Procuraduría Agraria, México.

López, Francisco, 2002a, Legislación y derechos indígenas en México. Centro de Orientación y Asesoría a Pueblos Indígenas-Ediciones Casa Vieja/La Guillotina-Ce Acatl, México. (Serie Derechos indígenas 3.)

—, 2002b, «Territorios, tierras y recursos naturales de los pueblos indígenas de México». En Constitución y Derechos Indígenas. Instituto de Investigaciones 
Jurídicas UNAM, México.

Moguel, Julio, 2004, «Acuerdos de San Andrés». En "presentación” Marco jurídico de la pluriculturalidad en México. Casa Juan Pablos, México.

—, 2004, «Convenio 169 de la OIT». En “presentación” Marco jurídico de la pluriculturalidad en México. Casa Juan Pablos, México.

Montañez, Gustavo, 2001, «Introducción. Razón y pasión del espacio y el territorio». En Espacio y Territorios. Razón, pasión e imaginarios. Universidad Nacional de Colombia, Colombia.

Pérez, Matilde, 2006, «El proyecto de ley agraria, golpe mortal al campo; es un regreso al porfirismo: CNC». En La Jornada, 9 de enero. México.

Salmerón Castro, Fernando y Odile Hoffmann (coords.), 1997, «Introducción. Entre representación y apropiación, las formas de ver y hablar del espacio». En Nueve estudios sobre el espacio, representaciones y formas de apropiación. CiesasOrstom, México.

Sánchez Consuelo, 1999, Los pueblos indígenas: del indigenismo a la autonomía. Siglo XXI, México.

Torres, Patricia, 2005, «Versión estenográfica de la entrevista de prensa que concedió el procurador agrario Dr. Isaías Rivera Rodríguez». En Sol de México, 9 de marzo. México.

Van Cott, Donna Lee, 2000, The Friendly Liquidation of the Past: The Politics of Diversity in Latin America. University of Pittsburgh Press, Pittsburg.

Ventura, María del Carmen, 1996, «Las reformas jurídicas en el campo y el Programa de Certificación de Derechos Ejidales y Titulación de Solares Urbanos (Procede). Estudio de caso: Michoacán». Tesis de licenciatura. Facultad de Ciencias Políticas y Sociales, UNAM, México.

Zúñiga, Gerardo, 1998, «Los procesos de constitución de territorios indígenas en América Latina». En Nueva Sociedad, núm. 153, pp. 141-155, enero-febrero. Friedrich Ebert Stiftung, Venezuela. 


\section{PÁGINAS ELECTRÓNICAS}

Acuerdo Nacional para el Campo. Por el Desarrollo de la Sociedad Rural y la Soberanía y Seguridad Alimentarias. Acuerdos: 237, 238, 239 y 240. http://www.inca.gob.mx/archivos_source/acuerdo\%20completo.pdf [Consulta 2 de agosto de 2006].

Declaración de Zirahuén. Declaración Política del Segundo Encuentro Nacional por la Defensa de la Tierra y el Territorio. http://www.derechoshumanos.org.mx/ [Consulta 18 de julio de 2006].

Gaceta Parlamentaria, LIX Legislatura, Cámara de Diputados, México, DF. http://gaceta.diputados.gob.mx/ [Consulta 30 de julio de 2006].

Organización de Naciones Unidas. Asamblea General. Consejo de Derechos Humanos. Declaración de las Naciones Unidas sobre los Derechos de los Pueblos Indígenas. http://www.cinu.org.mx/onu/onu.htm [consulta 30 de octubre de 2007].

Primera Declaración de la Selva Lacandona.

http://www.nodo50.org/pchiapas/chiapas/documentos/selva.htm [Consulta $28 \mathrm{de}$ julio de 2006].

REDSIAMA. http://www.redsiama.org/espanol/participacion_social.asp?Llave=37 [consulta 7 de agosto de 2006].

Registro Agrario Nacional: Dirección Nacional de Registro. Dirección de Sociedades y Acuerdos de Asamblea. Sociedades de Propiedades de Tierras Rústicas inscritas de 1992 al 30 de junio 2007. http://www.ran.gob.mx/ran/transparencia/Direccion\%20general\%20de\%20registro, \%20Actualizacion\%20\%202007(Junio)/sociedades\%20propietarias\%20de \%20tierras\%20rusticas.pdf [Consulta 3 de diciembre de 2007].

Registro Agrario Nacional. Dirección Nacional de Registro. Concentrado Histórico 2000-2007. Inscripción de Enajenación de Derechos correspondientes al integrantes de Ejidos incorporados al Procede, corte a junio 2007. http://www.ran.gob.mx/ran/transparencia/Direccion\%20general\%20de\%20regist ro, \%20Actualizacion\%20\%202007(Junio)/Inscripcion\%20de\%20enajenacion\%2 0de $\% 20$ derechos $\% 20$ correspondientes $\% 20 \% 20$ integrantes $\% 20 \mathrm{de} \% 201$ os $\% 20 \mathrm{eji}$ 
dos.pdf [Consulta 3 de diciembre de 2007].

Registro Agrario Nacional. Incorporación de tierras de dominio pleno al régimen ejidal. Acumulado histórico.

http://www.ran.gob.mx/ran/transparencia/Direccion\%20general\%20de\%20regist ro,\%20Actualizacion\%0\%202007(Junio)/incorporacion\%20de\%20tierras\%20del \%20dominio\%20pleno\%20al\%20regimen\%20ejidal.pdf $\quad[$ Consulta 3 de diciembre de 2007].

Registro Agrario Nacional. Núcleos agrarios que adoptaron el dominio pleno. Corte a junio de 2007.

http://www.ran.gob.mx/ran/transparencia/Direccion\%20general\%20de\%20regist ro,\%20Actualizacion\%20\%202007(Junio)/Dominio\%20Pleno\%20Concentrado. pdf [Consulta 3 de diciembre de 2007].

Secretaria de la Reforma Agraria, Fuente: Sistema Interinstitucional de Seguimiento, Evaluación y Control, SISEC. Avance a septiembre de 2006. http://www.sraeservicios.gob.mx/sra-e/dgia/fuentes/fichas.asp [Consulta 3 de diciembre de 2007].

Yorail Maya \#5. Revista del Centro de Derechos Humanos Fray Bartolomé de las Casas. http://www.laneta.apc.org/cdhbcasas/Yorail/Numero5/000-Indice.htm. [Consulta 16 de julio de 2006]. 


\section{Notas}

${ }^{1}$ Secretaría de la Reforma Agraria, Fuente: Sistema Interinstitucional de Seguimiento, Evaluación y Control, SISEC. Avance a septiembre de 2006. http://www.sra-eservicios.gob.mx/srae/dgia/fuentes/fichas.asp [Consulta 3 de diciembre de 2007].

${ }^{2}$ Ibid.

3 Yorail Maya \#5. Revista del Centro de Derechos Humanos Fray Bartolomé de Las Casas. http://www.laneta.apc.org/cdhbcasas/Yorail/Numero5/000-Indice.htm [Consulta 16 de julio de 2006].

${ }^{4}$ Declaración de Zirahuén. Declaración Política del Segundo Encuentro Nacional por la Defensa de la Tierra y el Territorio. http://www.derechoshumanos.org.mx/ [Consulta 18 de julio de 2006].

${ }^{5}$ Registro Agrario Nacional: Dirección Nacional de Registro. Dirección de Sociedades y Acuerdos de Asamblea. Sociedades de Propiedades de Tierras Rústicas inscritas de 1992 a 30 de junio de 2007. http://www.ran.gob.mx/ran/transparencia/Direccion\%20general\%20de\%20registro,\%20Actualizacion\%2 0\%202007(Junio)/sociedades\%20propietarias\%20de\%20tierras\%20rusticas.pdf [Consulta 3 de diciembre de 2007].

6 Registro Agrario Nacional. Dirección Nacional de Registro. Concentrado Histórico 2000-2007. Inscripción de Enajenación de Derechos correspondientes al integrantes de Ejidos incorporados al Procede, corte a junio 2007.

http://www.ran.gob.mx/ran/transparencia/Direccion\%20general\%20de\%20registro,\%20Actualizacion\%2 0\%202007(Junio)/Inscripcion\%20de\%20enajenacion\%20de\%20derechos\%20correspondientes\%20a\%20i ntegrantes\%20de\%20los\%20ejidos.pdf [Consulta 3 de diciembre de 2007].

${ }^{7}$ Registro Agrario Nacional. Incorporación de tierras de dominio pleno al régimen ejidal. Acumulado histórico.

http://www.ran.gob.mx/ran/transparencia/Direccion\%20general\%20de\%20registro,\%20Actualizacion\%2 0\%202007(Junio)/incorporacion\%20de\%20tierras\%20del\%20dominio\%20pleno\%20al\%20regimen\%20e jidal.pdf [Consulta 3 de diciembre de 2007].

${ }^{8}$ Registro Agrario Nacional. Núcleos agrarios que adoptaron el dominio pleno. Corte a junio de 2007. http://www.ran.gob.mx/ran/transparencia/Direccion\%20general\%20de\%20registro,\%20Actualizacion\%2 0\%202007(Junio)/Dominio\%20Pleno\%20Concentrado.pdf [Consulta 3 de diciembre de 2007].

${ }^{9}$ Primera Declaración de la Selva Lacandona: PUEBLO DE MÉXICO: Nosotros, hombres y mujeres íntegros y libres, estamos conscientes de que la guerra que declaramos es una medida última pero justa. Los dictadores están aplicando una guerra genocida no declarada contra nuestros pueblos desde hace muchos años, por lo que pedimos tu participación decidida apoyando este plan del pueblo mexicano que lucha por trabajo, tierra, techo, alimentación, salud, educación, independencia, libertad, democracia, justicia y paz.

${ }^{10}$ Artículo 76, fracción I, artículo 133 de la Constitución.

${ }^{11}$ Acuerdos de San Andrés. Documento 2. Fracción II. 5.

${ }^{12}$ Las cursivas son mías.

13 Acuerdo Nacional para el Campo. Por el Desarrollo de la Sociedad Rural y la Soberanía y Seguridad Alimentarias. Acuerdos: 237, 238, 239 y 240. 
http://www.inca.gob.mx/archivos_source/acuerdo\%20completo.pdf [Consulta 2 de agosto de 2006].

${ }^{14}$ El 16 de diciembre de 1996, por acuerdo del Secretario de la Reforma Agraria, se constituyó el Consejo Nacional Consultivo del Sector Agrario, Conacosa, que tiene entre sus funciones actuar como órgano de análisis, reflexión y consulta sobre temas agrarios; promover la participación de la sociedad en el desarrollo de las consultas; recoger las opiniones de la sociedad en materia agraria, y realizar estudios que contribuyan al enriquecimiento de la cultura agraria del país. Este acuerdo fue publicado en el Diario Oficial de la Federación el día 23 del mismo mes y año.

${ }^{15}$ Que no consideré indispensable relatar en este documento.

${ }^{16}$ Se desarrollaron cuatro foros: en Palacio Nacional, Oaxaca, Michoacán y Sinaloa.

${ }^{17}$ Dictamen del Proyecto de Decreto por el que se crea la Ley Federal Agraria, p. 15.

${ }^{18}$ Dictamen del Proyecto de Decreto por el que se crea la Ley Federal Agraria, p. 19.

${ }^{19}$ Ibid.

${ }^{20}$ Gaceta Parlamentaria, LIX Legislatura, Cámara de Diputados, México, DF. http://gaceta.diputados.gob.mx/ [Consulta 30 de julio de 2006].

${ }^{21}$ El 8 de enero de 2006, se anunciaba el voto en contra de la Iniciativa por parte de la CNC, con un comunicado a la prensa en el que su líder Heladio Ramírez afirmaba que la Iniciativa «tendría consecuencias peores a las dejadas en 12 años por el TLC debido a que abre las posibilidades de que por lo menos la mitad del territorio nacional que actualmente es propiedad social en manos de los campesinos pase a formar parte de la banca y las empresas trasnacionales que han desmantelado México» (comunicado de prensa). Pérez, Matilde, «El proyecto de ley agraria, golpe mortal al campo; es un regreso al porfirismo: CNC», La Jornada, 9 de enero de 2006.

${ }^{22}$ Los organismos empresariales que se manifestaron en contra fueron la Cámara de la Industria de la Transformación del Estado de Nuevo León, Caintra; Cementos Mexicanos, Cemex, y el Consejo Nacional Agropecuario (García 2006: 152).

${ }^{23}$ Otra de las posibles razones que explican el porqué del cambio de la votación del PRI, según plática informal con un legislador del PAN, es que CNC pretendía que del presupuesto de 2006 para el campo se le destinará para sus organizaciones un porcentaje importante, para lo cual condicionó su voto a favor de la Iniciativa de la Ley Federal Agraria. Al no lograrlo, manifestó su rechazo en la Cámara de Diputados votando en contra. Situación que dividió al propio grupo parlamentario del PRI, como se puede observar en los resultados de la votación.

${ }^{24}$ Las cursivas son mías.

${ }^{25}$ Las cursivas son mías.

${ }^{26}$ Así lo expresó Arthur Manuel del pueblo shushuap de Canadá en el cuarto periodo de sesiones del Foro Permanente para las Cuestiones Indígenas en Las Naciones Unidas, Nueva York de 16 a 27 de mayo de 2005, donde los representantes de los pueblos indígenas se pronunciaron críticamente sobre la nueva política del Banco Mundial sobre los pueblos indígenas. http://www.redsiama.org/espanol/participacion_social.asp?Llave=37 [Consulta 7 de agosto de 2006]. 
${ }^{27}$ Organización de Naciones Unidas. Asamblea General. Consejo de Derechos Humanos. Declaración de las Naciones Unidas sobre los Derechos de los Pueblos Indígenas. http://www.un.org/spanish/News/fullstorynews.asp?NewsID=10347 [Consulta 8 de agosto de 2006]

28 «La Iniciativa que ya está en la Cámara de Diputados, es una Iniciativa histórica hasta cierto punto como lo dice el Secretario de la Reforma Agraria, porque hay un consenso entre las organizaciones, gobierno e intelectuales que pudieron llegar a un acuerdo» (Sol de México, 9 de marzo de 2005).

Fecha de recepción: 20 de septiembre de 2007.

Fecha de aceptación: 21 de noviembre de 2007. 